\title{
Impact of tumor necrosis factor inhibitors and methotrexate on diabetes mellitus among patients with inflammatory arthritis
}

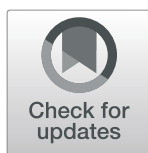

Santhi Mantravadi ${ }^{1,2}$, Michael George ${ }^{2,3}$, Colleen Brensinger ${ }^{3}$, Min Du ${ }^{3}$, Joshua F. Baker ${ }^{2,3}$ and Alexis Ogdie ${ }^{2,3^{*}}$ (D)

\begin{abstract}
Background: To determine whether initiation of a tumor necrosis factor inhibitor (TNFi) or methotrexate improves hemoglobin A1c in patients with psoriatic arthritis (PsA), rheumatoid arthritis (RA), or ankylosing spondylitis (AS) who also have diabetes mellitus (DM).

Methods: A retrospective cohort study was conducted in Optum's de-identified Clinformatics ${ }^{\circledR}$ Data Mart Database, an administrative claims database, using data from 2000 to 2014. Patients with PsA, RA, or AS, with DM (defined by ICD-9-CM codes) and/or HbA1c $\geq 7 \%$, who newly initiated either a TNFi, MTX, or metformin (positive control) were identified. The change in $\mathrm{HbA1c}$ after drug initiation was calculated. Statistical differences in the change in HbA1c between drugs were assessed using the Wilcoxon rank sum test and linear regression models adjusting for potential confounders.

Results: Among 10,389 drug initiations in 9541 patients with PsA, RA, or AS, and available HbA1c values, HbA1c was $\geq 7$ at baseline in 254 (35\%) TNFi initiations, 361(37\%) MTX initiations, and 2144 (50\%) metformin initiations. Median HbA1c change was -0.35 (IQR -1.10, 0.30) after TNFi initiation, $-0.40($ IQR -1.20, 0.30) after MTX initiation, and -0.80 (IQR -1.60, - 0.10) after metformin initiation. In adjusted analyses, TNFi initiators had less of a decrease in HbA1c compared to MTX initiators ( $\beta 0.22,95 \% \mathrm{Cl}: 0.004,0.43$ ), $p=0.046$. Metformin initiators had a significantly greater decrease in HbA1c than MTX, $\beta-0.38$ ( $95 \% \mathrm{Cl}$ : - 0.52, - 0.23), $p<0.001$. Glucocorticoid use was not accounted for in the models.
\end{abstract}

Conclusion: HbA1c decreased with TNFi initiation or MTX initiation. Reductions in HbA1c after initiation of a TNFi or MTX are about half ( 0.4 units) the decrease observed after initiation of metformin.

Keywords: Psoriatic arthritis, Rheumatoid arthritis, Ankylosing spondylitis, Diabetes mellitus, Outcomes, Epidemiology

\footnotetext{
* Correspondence: alogdie@pennmedicine.upenn.edu

${ }^{2}$ Department of Medicine, Division of Rheumatology, Perelman School of Medicine, University of Pennsylvania, White Building Rm 5023, 3400 Spruce St, Philadelphia, PA 19104, USA

${ }^{3}$ Department of Biostatistics, Epidemiology, and Informatics, Division of Rheumatology, Perelman School of Medicine, University of Pennsylvania, 423 Guardian Dr, Philadelphia, PA 19104, USA

Full list of author information is available at the end of the article
}

\section{Background}

RA, PsA, and AS are chronic debilitating inflammatory joint diseases associated with significant comorbidities such as DM, cardiovascular disease, and depression [14]. Incidence and prevalence of DM is increased in patients with RA, PsA and AS patients, affecting approximately $10 \%$ or more of patients with IA [1, 3, 5-8].

Tumor necrosis factor (TNF)- $\alpha$, an inflammatory cytokine, is a key player in the pathogenesis of RA, PsA, AS,

(C) The Author(s). 2020 Open Access This article is licensed under a Creative Commons Attribution 4.0 International License, which permits use, sharing, adaptation, distribution and reproduction in any medium or format, as long as you give appropriate credit to the original author(s) and the source, provide a link to the Creative Commons licence, and indicate if changes were made. The images or other third party material in this article are included in the article's Creative Commons licence, unless indicated otherwise in a credit line to the material. If material is not included in the article's Creative Commons licence and your intended use is not permitted by statutory regulation or exceeds the permitted use, you will need to obtain permission directly from the copyright holder. To view a copy of this licence, visit http://creativecommons.org/licenses/by/4.0/. The Creative Commons Public Domain Dedication waiver (http://creativecommons.org/publicdomain/zero/1.0/) applies to the data made available in this article, unless otherwise stated in a credit line to the data. 
and type II DM. Elevated local and circulating levels of TNF- $\alpha$ in RA, PsA, and AS contribute to the inflammatory and structural changes in these inflammatory conditions [9-11]. In type II diabetes, a chronic inflammatory state exists, marked by increased cytokines such as TNF$\alpha$, IL-1, and IL-6 [12]. Patients with inflammatory arthritis were also found to have greater insulin resistance compared to controls, and this was particularly true for PsA [13]. TNF- $\alpha$ has been found to promote insulin resistance [14, 15] and disrupt insulin signaling [16, 17]. Thus, it may be presumed that modulating this pathway in IA patients with diabetes may improve insulin sensitivity. In several studies, the Homeostatic Model Assessment for Insulin Resistance (HOMA-IR index), which reflects insulin resistance, decreased with TNFi therapy in RA patients [18-21]. Additionally, another study suggested that infliximab treatment in RA and AS patients may improve insulin sensitivity in patients with high insulin resistance [22]. This study did not compare TNFi use to other common DMARDs.

Little is known about the role of MTX in insulin resistance and existing studies have conflicting messages. One study observed decreases in HbA1c in RA and PsA patients without diabetes taking MTX [23]. In addition, the prevalence of metabolic syndrome in patients with RA was found to be lower among patients using methotrexate, though this data may be confounded by the steatohepatitis leading to discontinuation of methotrexate [24]. However, in a large retrospective study of patients with RA or psoriasis, use of a TNFi was associated with a decreased risk for diabetes whereas use of methotrexate was not [25]. In other studies, significant decreases were not seen in the HOMA-IR index with initiation of MTX [23, 24, 26].

Overall, little is known about how TNFi and MTX impact $\mathrm{HbA1c}$ in patients with IA and diabetes. The goal of this study was to determine whether HbA1c improves in DM patients with RA, PsA, or AS initiating a TNFi compared to patients initiating MTX in a large realworld cohort. We hypothesized that patients using TNFi would have a greater reduction in HbA1c than patients initiating methotrexate based on the pathophysiologic role of TNF in diabetes.

\section{Methods}

\section{Study design and data source}

A retrospective cohort study was conducted in Clinformatics $^{\text {sm }}$ Data Mart (OptumInsight, Eden, Prairie, MN), a de-identified administrative claims database in the United States that includes demographic data, prescription drug use, diagnostic codes, medical claims history, and laboratory values (approximately 10\% of patients) for approximately 13 million beneficiaries. We identified patients with RA, PsA, or AS with an $\mathrm{HbA1c} \geq 7$ and examined change in HbA1c among new initiators of a TNFi (etanercept, adalimumab, certolizumab, golimumab, or infliximab), MTX, or metformin (positive control). In addition, we studied all patients with IA and DM fulfilling criteria defined by ICD-9-CM codes and with a baseline HbA1c regardless of the value ("DM criteria cohort").

\section{Study time period}

Data from 2000 to 2014 were included. The index date was the date of TNFi, MTX, or metformin initiation. A baseline period any time prior to the index date was required to capture potential confounders [27-29]. All patients were required to have one $\mathrm{HbA} 1 \mathrm{c}$ in the 6 months prior to and one HbAlc in the 3-12 months after drug initiation. Follow up HbA1C was at least 3 months from the prior value and 3 months from initiating the medication. (Fig. 1).

\section{Study population}

Patients $\geq 18$ years of age with at least one diagnosis code for PsA (ICD-9-CM 696.0), or RA (ICD-9-CM 714.0714.33), or AS (ICD-9-CM 720.0) prior to therapy initiation, and a prescription for a disease-modifying antirheumatic drug (DMARD) were included in the cohort. Studies have shown a higher PPV when diagnosis codes are combined with DMARD prescriptions to identify PsA, RA, and AS patients in health care utilization databases [30-35]. In a sensitivity analysis, we allowed patients to acquire the code for IA at any point during follow up. Among patients with IA, we identified diabetes using diagnosis codes (ICD-9-CM 249.xx, 250.xx, $357.2,362.01-06,366.41)$ [36, 37]. The primary analysis included patients with a HbA1c $\geq 7$. In a secondary analysis, we included patients who met "DM criteria." These patients were required to have one inpatient code or two outpatient codes at any point in the database (PPV approximately 90\%) [38]. Similar definitions have been used in prior studies $[39,40]$. The distinction was not made between Type I and Type II DM, but given the age of the cohort, the patients are likely to predominantly have Type II DM [41].

\section{Exposures}

The primary exposures of interest were new initiations of TNFi (etanercept, adalimumab, certolizumab, golimumab, or infliximab) and MTX (oral or subcutaneous). Medications were identified using National Drug Codes (NDC). We used a new user design in which patients were initiating a new TNFi or methotrexate and had not previously had a prescription for the therapy initiated. Patients may have had a prior exposure to a different TNFi. Patients were required to have at least 12 months in the dataset prior to therapy initiation to evaluate prior 


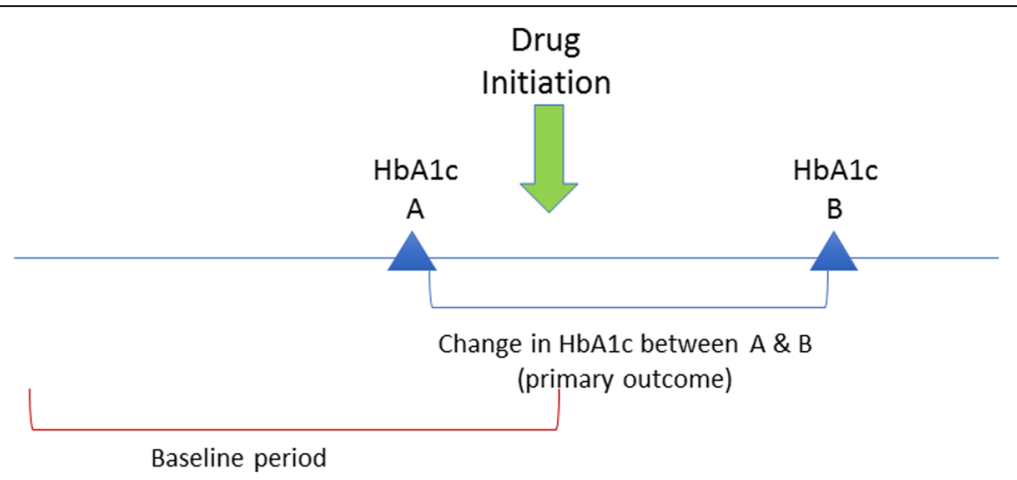

Fig. 1 Study Design and Study Time Period. Start date is the date of drug initiation (TNFi, MTX, or metformin). A baseline period prior to the drug start date was required to capture any potential confounders. Baseline $\mathrm{HbA1c}(\mathrm{HbA} 1 \mathrm{C} \mathrm{A}$ ) must have occurred within the 6 months prior to medication initiation. Follow up HbA1C ( $\mathrm{HbA1C} B$ ) was at least 3 months from the prior value and three to 12 months from initiating the medication. Change in $\mathrm{HbA1c}$ value from before to after drug initiation was reported for TNFi, MTX, and metformin users (primary outcome). Abbreviations: $\mathrm{HbA1c}=$ hemoglobin A1c; MTX = methotrexate; TNFi = tumor necrosis factor inhibitor

exposures and to ensure new drug start. We additionally included metformin as a "positive control" using similar definitions.

\section{Outcome definition}

The outcome of interest was the absolute change in HbA1c after initiation of a TNFi, MTX, or metformin.

\section{Covariates}

We examined baseline demographics, comorbidities, and medications, and their impact on HbA1c change. These included age, sex, anemia, angina, aortic aneurysm, asthma, anxiety, atrial fibrillation, baseline diabetes medications, baseline methotrexate, baseline TNFi, bipolar disorder, cancer, cardiomyopathy, chronic kidney disease, chronic obstructive pulmonary disease, connective tissue disease, cerebrovascular disease, congestive heart failure, coronary artery disease, degenerative disc disease, dementia, depression, diabetic retinopathy, giant cell arteritis, hypertension, hypothyroidism, inflammatory bowel disease, lung disease, metabolic syndrome, mixed connective tissue disease, myocardial infarction, obesity, obstructive sleep apnea, osteoarthritis, peptic ulcer disease, peripheral arterial disease, peripheral vascular disease, pulmonary embolism, polymyalgia rheumatica, pregnancy, psoriasis, other psychiatric disorders, rheumatoid arthritis-lung, SICCA syndrome, sleep disorder, systemic lupus erythematous, systemic sclerosis, and uveitis. These covariates were defined by plan demographic information, ICD-9-CM codes, and NDC codes. We specifically did not adjust for glucocorticoids as glucocorticoids may be on the causal pathway.

\section{Statistical analysis}

All statistical analysis was performed using STATA 15.0 (StataCorp, College Station, TX, USA). The primary analysis (among patients with $\mathrm{HbA1c} \geq 7$ ) and secondary analysis (DM criteria cohort) were performed in the same manner. Median HbA1c change was calculated (given non-normal distribution), and the Wilcoxon signed-rank test was used to assess the difference in A1c change between baseline A1c change and A1c change after initiation of the medication. The Wilxocon rank sum test was then used to assess the unadjusted statistical differences between the medication groups.

Univariable and multivariable linear regression models were used to determine the relative differences in HbA1c change using MTX as the reference and adjusted for potential confounders. Variables examined as confounders include age, sex, baseline HbA1c, baseline DM medications, baseline MTX use (for patients on TNFi), and baseline comorbidities. Estimates from regression models considered clustering on patients to account for the presence of multiple new drug initiations per patient. In sensitivity analyses, we only allowed patients to contribute one therapy initiation and we included calendar year in the multivariable models.

\section{Ethics approval}

This study was considered exempt by University of Pennsylvania Institutional Review Board.

\section{Results}

A total of 10,389 drug initiations in 9541 patients with PsA, RA, or AS, and HbA1c values available were identified: 690, 3681, and 1585 drug initiations with PsA, RA, and AS diagnoses respectively in the baseline period were identified (disease groups are not mutually exclusive, Fig. 2). Of these, there were 731 TNFi initiations, 972 MTX initiations, and 4253 metformin initiations. HbA1c was $\geq 7$ before treatment initiation (the HBA1c $\geq$ 7 cohort) in 254 (35\%) TNFi users, 361 (37\%) MTX 


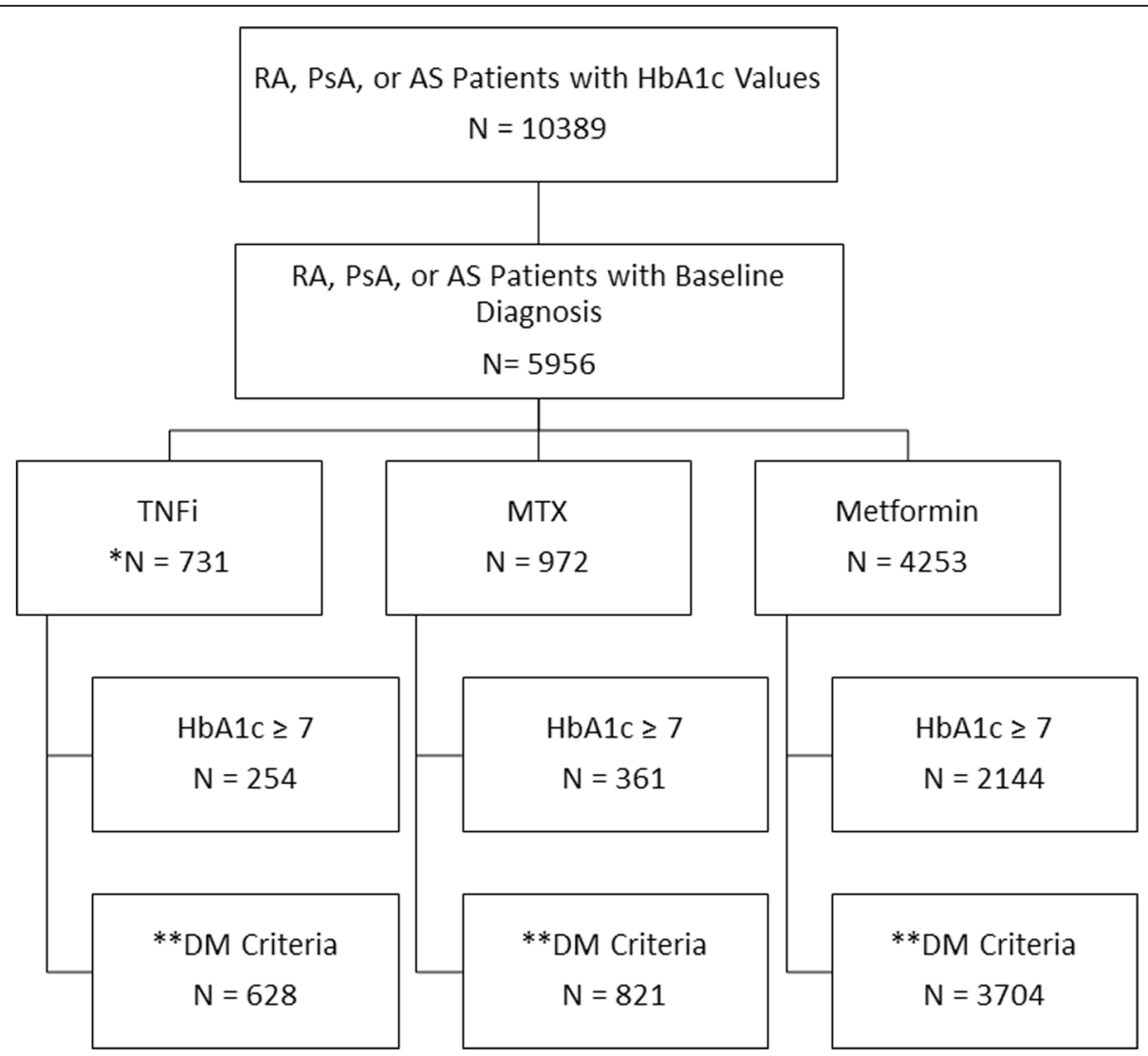

Fig. 2 Flow Diagram: Derivation of the Cohorts. The HbA1c $\geq 7$ \& DM criteria cohorts are not mutually exclusive. *Patients were allowed to enter the TNFi group multiple times with each initiation of a different TNFi. **DM criteria cohort: all patients with DM fulfilling criteria by ICD-9-CM codes and with a baseline HbA1c regardless of the value of the HbA1c. Abbreviations: AS = ankylosing spondylitis; DM=diabetes mellitus; $\mathrm{HbA1C}=$ hemoglobin A1c; MTX = methotrexate; PSA = psoriatic arthritis; RA = rheumatoid arthritis; TNFi = tumor necrosis factor inhibitor

users, and 2144 (50\%) metformin users. DM criteria was fulfilled with no restriction on baseline HbA1c value (the DM criteria cohort) in 628 (86\%) TNFi initiations, 821 (84\%) MTX initiations, and 3704 (87\%) metformin initiations.

Baseline characteristics of the populations are shown in Table 1. In the HbA1c $\geq 7$ cohort, the mean age of the TNFi group, MTX group, and metformin group was approximately 45 years. All three groups were predominantly female (60-68\%). The mean number of days between the baseline HbA1c and follow-up HbA1c was similar across all three groups (201-241 days). There was a high prevalence of dyslipidemia and hypertension, as expected in a diabetes cohort [42-44]. More patients in the elevated HbA1c group were on diabetes medications in the baseline period than those in the DM criteria cohort (TNFi $91 \%$ vs $76 \%$, MTX $88 \%$ vs $72 \%$ ). Baseline characteristics were similar between the primary cohort $(\mathrm{HbA} 1 \mathrm{c} \geq 7)$ and the DM criteria cohort (Suppl Table 1).

In the $\mathrm{HbA} 1 \mathrm{c} \geq 7$ cohort, the median HbA1c change was -0.35 (IQR $-1.10,0.30$ ) after TNFi initiation, -0.40
(IQR -1.20, 0.30) after MTX initiation, and - 0.80 (IQR $-1.60,-0.10)$ after metformin initiation. In unadjusted analysis, there was no significant difference in the median HbA1c change between TNFi and MTX $(p=0.46)$. There was a statistically significant difference in the median HbA1c change between TNFi and metformin $(p<$ $0.001)$ and between MTX and metformin $(p<0.001)$.

In the cohort with $\mathrm{HbA} 1 \mathrm{c} \geq 7$, after adjustment for age, sex, baseline HbA1c, and baseline comorbidities, metformin initiators had a significantly greater decrease in HbA1c than MTX initiators, $\beta-0.38$ (95\%CI: -0.52 , -0.23 ), $p<0.001$ (Table 2, Fig. 3, Suppl Figure 1). TNFi initiators had less of a decline in HbA1c compared to MTX initiators (resulting in a positive beta coefficient: $\beta$ 0.22 (95\%CI: 0.004, 0.43), $p=0.046$.

When conducting the same analyses in the broader DM criteria cohort, the median HbA1c change was 0 (IQR -0.50, 0.30) after TNFi initiation, 0 (IQR -0.50, 0.40) after MTX initiation, and - 0.30 (IQR -1.0, 0.10) after metformin initiation. In unadjusted analysis, there was not a statistically significant difference in the median HbA1c change between TNFi and MTX. There was a 
Table 1 Baseline Characteristics: HbA1c $\geq 7$ Cohort

\begin{tabular}{|c|c|c|c|c|c|}
\hline & $\begin{array}{l}\operatorname{MTX}(N= \\
361)\end{array}$ & $\begin{array}{l}\text { TNFi }(N= \\
254)\end{array}$ & $\begin{array}{l}\text { Metformin }(N= \\
\text { 2144) }\end{array}$ & $\begin{array}{l}\text { SMD TNF VS } \\
\text { MTX }\end{array}$ & $\begin{array}{l}\text { SMD Met vs } \\
\text { MTX }\end{array}$ \\
\hline Mean age, years (SD) ${ }^{a}$ & $45(3)$ & $45(3)$ & $45(3)$ & 0 & 0 \\
\hline Male sex $(\%)^{b}$ & $37 \%$ & $32 \%$ & $40 \%$ & -0.15 & 0.08 \\
\hline Baseline $\mathrm{HbA1c}$ & 8.29 & 8.31 & 8.41 & -0.02 & 0.07 \\
\hline \multicolumn{6}{|l|}{ Comorbidities, N (\%) } \\
\hline Anemia & $55(15 \%)$ & $29(11 \%)$ & $232(11 \%)$ & -0.11 & -0.11 \\
\hline Angina & $59(16 \%)$ & $28(11 \%)$ & $227(11 \%)$ & -0.15 & -0.15 \\
\hline Anxiety & 35 (10\%) & $39(15 \%)$ & $375(17 \%)$ & 0.15 & 0.21 \\
\hline Asthma & $73(20 \%)$ & 48 (19\%) & $388(18 \%)$ & -0.03 & -0.05 \\
\hline CAD & $121(34 \%)$ & $60(24 \%)$ & $544(25 \%)$ & -0.22 & -0.20 \\
\hline $\mathrm{CHF}$ & 49 (14\%) & $28(11 \%)$ & $251(12 \%)$ & -1.46 & -0.16 \\
\hline CKD & 103 (29\%) & $56(22 \%)$ & $360(17 \%)$ & -0.28 & -0.52 \\
\hline COPD & $56(16 \%)$ & $48(19 \%)$ & $393(18 \%)$ & 0.08 & 0.05 \\
\hline Cardiomyopathy & $19(5 \%)$ & $9(4 \%)$ & $88(4 \%)$ & -0.25 & -0.25 \\
\hline Other CTD & $21(6 \%)$ & $12(5 \%)$ & $67(3 \%)$ & 0.20 & 0.71 \\
\hline Depression & 71 (20\%) & $65(26 \%)$ & $503(23 \%)$ & 0.26 & 0.14 \\
\hline DM retinopathy & $64(18 \%)$ & $42(17 \%)$ & $29(1 \%)$ & -0.06 & -1.37 \\
\hline Hypertension & $316(88 \%)$ & $217(85 \%)$ & $1807(84 \%)$ & -0.03 & -0.05 \\
\hline Hypothyroidism & $112(31 \%)$ & $88(35 \%)$ & $671(31 \%)$ & 0.12 & 0.00 \\
\hline Dyslipidemia & $312(86 \%)$ & $225(89 \%)$ & $1825(85 \%)$ & 0.03 & -0.01 \\
\hline Inflammatory bowel disease & $9(2 \%)$ & $12(5 \%)$ & $44(2 \%)$ & 0.90 & 0.00 \\
\hline Liver disease & $88(24 \%)$ & $64(25 \%)$ & $408(19 \%)$ & 0.04 & -0.24 \\
\hline Myocardial infarction & $23(6 \%)$ & $8(3 \%)$ & $36(2 \%)$ & -0.71 & -1.00 \\
\hline Obesity & $98(27 \%)$ & $72(28 \%)$ & $629(29 \%)$ & 0.04 & 0.07 \\
\hline Psoriasis & $43(12 \%)$ & $81(32 \%)$ & $154(7 \%)$ & 0.84 & -0.54 \\
\hline Baseline diabetes medications, N (\%) & $316(88 \%)$ & $232(91 \%)$ & $2144(100 \%)$ & 0.03 & 0.13 \\
\hline Baseline MTX, N (\%) & - & $128(50 \%)$ & $274(13 \%)$ & $\mathrm{n} / \mathrm{a}$ & $\mathrm{n} / \mathrm{a}$ \\
\hline Baseline TNFi, N (\%) & $36(10 \%)$ & $84(33 \%)$ & $214(10 \%)$ & 0.96 & 0.00 \\
\hline Baseline Steroids ${ }^{c}, N(\%)$ & $152(42 \%)$ & $100(39 \%)$ & $394(18 \%)$ & -0.07 & -0.75 \\
\hline Average baseline glucocorticoid dose, mean (SD) & $6(7)$ & $6(6)$ & $5(7)$ & 0 & 0.14 \\
\hline Duration btwn baseline and f/up HbA1c, mean \# of days (SD) & $241(83)$ & $237(84)$ & $201(79)$ & 0.05 & -0.49 \\
\hline $\begin{array}{l}\text { Duration btwn med start date and f/up HbA1c, mean \# of } \\
\text { days (SD) }\end{array}$ & $173(66)$ & $166(65)$ & $168(66)$ & -0.11 & -0.08 \\
\hline
\end{tabular}

$N$ number of observations

TNFi, MTX, and metformin groups are not mutually exclusive

${ }^{a}$ In the metformin group, one observation is missing for age

${ }^{b}$ In the metformin group, two unknown observations for sex were changed to missing

'Six-month baseline period

Abbreviations: CAD Coronary artery disease, CKD Chronic kidney disease, CTD Connective tissue disease (ICD9 code 710.9 , not inclusive of SLE, sicca, or scleroderma), COPD Chronic obstructive pulmonary disease, CHF Congestive heart failure, DM Diabetes mellitus, HbA1c Hemoglobin A1c, MTX Methotrexate, SMD Standardized mean difference, TNFi Tumor necrosis factor inhibitor

statistically significant difference in the median $\mathrm{HbA1c}$ change between TNFi and metformin $(p<0.001)$ and between MTX and metformin $(p<0.001)$. When compared to MTX initiators, TNFi initiators had a similar change in HbA1c in this expanded cohort, $\beta 0.03$ (95\%CI: $0.07,0.14), p=0.552$. Metformin initiators had a significantly greater negative change in HbA1c than MTX initiators, $\beta-0.30$ (95\%CI: $-0.38,-0.21), \quad p<0.001$ (Suppl Table S2, Suppl Figure 2).

We performed several sensitivity analyses to test assumptions made (Suppl Table S3, Suppl Table S4). First, we examined change in $\mathrm{Hb} 1 \mathrm{Ac}$ by disease to determine whether there were differences for one particular disease group. The effect sizes were similar to the main results. 
Table 2 Associations Between Treatment Initiation and Change in $\mathrm{HbA} 1 \mathrm{c}$ in Patients with Baseline $\mathrm{HbA} 1 \mathrm{c} \geq 7$

\begin{tabular}{|c|c|c|c|c|}
\hline \multirow[t]{2}{*}{ Variable } & \multicolumn{2}{|c|}{ Univariable Model } & \multicolumn{2}{|c|}{ Multivariable Model } \\
\hline & $\overline{\beta^{a}}$ & $95 \% \mathrm{Cl}$ & $\overline{\beta^{a}}$ & $95 \% \mathrm{Cl}$ \\
\hline \multicolumn{5}{|l|}{ Treatment initiation } \\
\hline Methotrexate & Ref & - & Ref & - \\
\hline TNFi & 0.20 & $-0.04,0.43$ & 0.22 & $0.004,0.43$ \\
\hline Metformin & -0.48 & $-0.66,-0.30$ & -0.38 & $-0.52,-0.23$ \\
\hline Age (years) & 0.01 & $-0.01,0.03$ & -0.002 & $-0.02,0.01$ \\
\hline Sex (female) & -0.25 & $-0.38,-0.12$ & -0.20 & $-0.30,-0.10$ \\
\hline Baseline $\mathrm{HbA1c}$ & -0.68 & $-0.73,-0.63$ & -0.68 & $-0.73,-0.62$ \\
\hline Atrial Fibrillation & 0.24 & $0.03,0.45$ & & \\
\hline CAD & 0.20 & $0.06,0.33$ & & \\
\hline Cardiomyopathy & 0.35 & $0.02,0.69$ & 0.30 & $0.03,0.57$ \\
\hline Other CTD & -0.42 & $-0.76,-0.08$ & -0.43 & $-0.64,-0.22$ \\
\hline CVD & 0.24 & $0.06,0.41$ & & \\
\hline Dementia & 0.50 & $0.19,0.82$ & & \\
\hline Hypertension & 0.25 & $0.05,0.45$ & & \\
\hline Dyslipidemia & 0.28 & $0.09,0.46$ & 0.15 & $0.01,0.29$ \\
\hline Myocardial Infarction & 0.66 & $0.26,1.06$ & 0.46 & $0.07,0.85$ \\
\hline PVD & 0.28 & $0.08,0.48$ & & \\
\hline Pulmonary Embolism & 0.58 & $0.14,1.03$ & & \\
\hline
\end{tabular}

${ }^{a}$ Beta-coefficients are interpreted as the mean difference in the outcome (HbA1c) in the target group (TNF or Metformin) minus the reference group (MTX)

Variables tested that were not significant at the univariable stage were not included in this table: The following variables are not significant at the univariable stage: anemia, angina, anxiety, aortic aneurysm, asthma, baseline diabetes medications, baseline methotrexate, baseline TNFi, bipolar disorder, cancer, chronic kidney disease, chronic obstructive pulmonary disease, congestive heart failure, coronary heart disease, degenerative disc disease, depression, diabetic retinopathy, giant cell arteritis, hypothyroidism, inflammatory bowel disease, liver disease, lung disease, metabolic syndrome, mixed connective tissue disease, obesity, obstructive sleep apnea, osteoarthritis, peptic ulcer disease, peripheral arterial disease, polymyalgia rheumatica, pregnancy, psoriasis, other psychiatric disorders, rheumatoid arthritis-lung, SICCA syndrome, sleep disorder, systemic lupus erythematous, systemic sclerosis, and uveitis

Abbreviations: CAD Coronary artery disease, CTD Connective tissue disease (ICD9 code 710.9, not inclusive of SLE, sicca, or scleroderma), CVD Cerebrovascular disease, HbA1c Hemoglobin A1C, PVD Peripheral vascular disease, TNFi Tumor necrosis factor inhibitor

After excluding patients with baseline glucocorticoid use, there was a smaller difference between TNFi and MTX initiators but results were similar in the metformin group. Similarly, adjusting for baseline TNFi exposure and allowing patients to only contribute one drug initiation did not differ from the results of the final model. We additionally repeated all of the analyses in the cohort of patients with diabetes but not restricted to $\mathrm{HbA} 1 \mathrm{c} \geq 7$ (Suppl Table S5 and Suppl Table S6). Neither of the sensitivity analyses (adding calendar year to the model and restricting patients to a single therapy initiation) significantly changed the results.

\section{Discussion}

In this retrospective cohort study in patients with DM and inflammatory arthritis, we found that, among patients with an elevated HbA1c at baseline, patients treated with TNFi and MTX had, on average, a small decrease in HbA1c that was approximately half of that seen with metformin initiation. We initially hypothesized, based on the mechanism of the TNFi, that TNFi would result in a greater decrease in HbA1c than MTX, but found that overall they were similar. These findings potentially support the concept that modulating inflammation associated with inflammatory arthritis may have off target benefits regardless of the therapy. We acknowledge the changes seen in this study were small and were not observed among all patients with diabetes when including patients with normal HbA1cs at baseline. Thus, additional studies are needed to confirm these results.

Few studies have evaluated the association between TNFi and their effect on fasting plasma glucose (FPG) and $\mathrm{HbA} 1 \mathrm{c}$ values in inflammatory arthritis patients that also have a diagnosis of diabetes. In a six-month retrospective cohort study in psoriasis patients without diabetes treated with etanercept, infliximab, or methotrexate, there were no significant changes in FPG associated with any of the medications [45]. A 24-week study that evaluated nine non-diabetic psoriasis patients on etanercept did not find a significant difference in HbA1c and FPG values [46]. One small retrospective study assessing HbA1c, FPG, and fasting triglyceride levels in eight patients with RA or Crohn's disease on etanercept or infliximab concluded that TNFi can improve glucose control in diabetic patients [47]. A randomized, double-blind study assessing diabetic patients with RA on etanercept versus a placebo control through week 12 and then an open label phase through week 24 found a slight decrease in FPG through week 12 and a slight decrease in HbA1c through week 24, but was not significant [48]. A retrospective study that evaluated a subgroup of patients with DM and RA $(n=75)$ found a significant decrease in $\mathrm{HbA} 1 \mathrm{c}$ values after initiation of a TNFi [49]. Thus far, the findings above demonstrate an inconsistent effect of TNFi on HbAlc and/or FPG. To date, no studies have directly compared the effects of methotrexate versus TNFi on HbA1c values in patients with diabetes.

A handful of studies have also investigated change in HbA1c after treatment with a TNFi among patients without diabetes. One study assessed HbA1c and FPG values in psoriasis, PsA, or RA patients, the majority of which were non-diabetic, after initiation of etanercept, infliximab, adalimumab, or golimumab, versus methotrexate did not find a significant change in $\mathrm{HbA1c}$ or FPG [50]. A study of 39 AS patients and 18 PsA patients without diabetes did not demonstrate any change in mean FPG levels after initiating adalimumab, infliximab, or etanercept in the first 6 months of treatment [51]. Thus, both small studies found no significant benefit of 


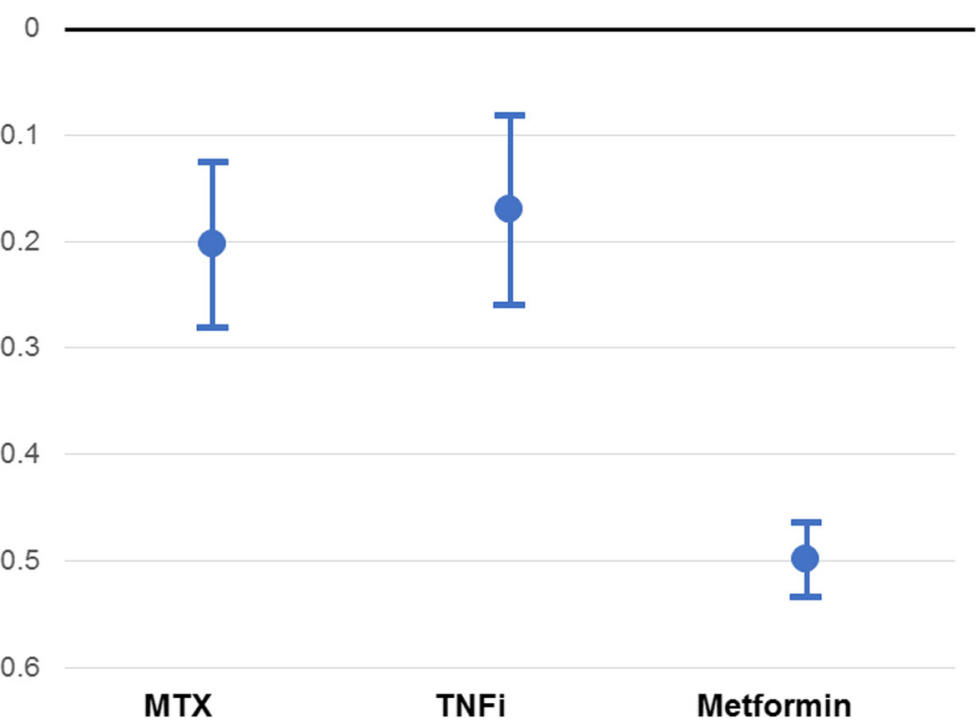

Fig. 3 Predicted Change in HbA1c in baseline A1c $\geq 7$ cohort after TNFi, MTX, or Metformin Initiation. Predicted change in HbA1c from linear regression models adjusted for age, sex, baseline HbA1c, baseline DM medications, baseline MTX use (for patients on TNFi), and baseline comorbidities. Abbreviations: $\mathrm{DM}=$ diabetes mellitus; $\mathrm{HbA1c}=$ hemoglobin A1c; MTX = methotrexate; TNFi = tumor necrosis factor inhibitor

TNFi on insulin resistance or HbA1c values in this patient population.

In designing this study, we focused primarily on patients with DM and with elevated HbA1c values as we felt that the off target effects of TNFi and MTX are of greater clinical importance in this population. In our study, we found greater improvements in HbAlc among the cohort with an elevated HbA1c at baseline than those with diabetes but not required to have an elevated baseline HbA1c. This likely is secondary to the fact that there was more room to change in the $\mathrm{HbA1c} \geq 7 \mathrm{co}-$ hort; these patients were more likely to have uncontrolled DM at baseline. It is possible that HbA1c improved in all three treatment groups in this population due to regression to the mean. It was for this reason that we included the metformin group as a comparator and also examined all patients with diabetes. In the full diabetes population, the already small differences between MTX and TNFi were further attenuated, but overall, the results did not substantially change. Importantly, the effect was similar for both MTX and TNFi suggesting that they still had similar effects on HbA1c regardless of the patient population.

Potential limitations of the study include defining the diseases by diagnostic codes and limited knowledge of adherence to therapy (only prescriptions filled). Additionally, relatively long gaps between the baseline and follow-up HbA1c could have affected our results given the greater chance for factors such as medication changes, lifestyle (i.e., dietary) changes, and potential hospitalizations to affect HbA1c values. Gaps were similar between treatment arms including among the metformin group, however, which was included as a positive control. Similarly, patients with elevated HbA1c may have improved even without a therapy change. We did not examine patients not changing therapy in this study as it was not part of the original study question but may be one way to address the concern for regression to the mean. Next, we acknowledge that glucocorticoids can increase blood sugar. Accounting for glucocorticoid use is challenging given that it is likely on the causal pathway between treatment and $\mathrm{HbA1c}$ values. For this reason, we did not adjust for prednisone use nor account for prednisone use in time varying models. Similarly, use of diabetes medications were not accounted for in a time varying manner as they are on the causal pathway. We instead adjusted for use of diabetes medications at baseline. Next, in comparing methotrexate users to TNFi users, confounding by indication may exist (i.e., use of a TNF inhibitor may be associated with worse disease activity or longer disease duration, neither of which are measured in these datasets). We suspect that the confounding would have biased away from the null in the comparison of the two drugs; however, we found that TNFi and MTX had similar effects. Next, we selected a group of patients who had laboratory values available which are generally provided from two large laboratory vendors, likely requiring a certain type of insurance plan and that patients actually went to the lab to have their labs drawn. This may have caused a selection bias. We are unable to compare those with and without laboratory values as we only have patients with the lab values in the dataset. Finally, there was not a significant difference between TNFi and 
MTX. This could have been related to the relatively small sample size. However, there were enough patients available to identify a meaningful difference. Many of these limitations, including the need to examine the subset of the population with lab values, would be a limitation of any observational data source, but regardless, should be considered in interpretation of the findings.

Our study also has several strengths. We evaluated a large cohort of patients with RA, PsA, or AS with a diagnosis of DM. Optum contains one of the largest populations of RA, PsA, and AS patients and is a good representation of the United States insured population. Even after restricting to patients with lab values at the required time points, our sample size was relatively large. Finally, the use of metformin as a positive control provides internal and external validity to our study results.

\section{Conclusions}

In conclusion, initiation of a TNFi or MTX among patients with an elevated HbA1c is associated with a modest decrease in $\mathrm{HbA1c}$ that is approximately half as much ( 0.4 units) as the decrease observed after initiation of metformin ( $\sim 0.8$ units). This study found no compelling evidence for a difference in the effect between TNFi and MTX, suggesting similar treatment effects. This study suggests that, in addition to limiting glucocorticoid exposure in patients with diabetes, controlling inflammatory disease may have off-target benefits, regardless of the drug choice. Future research is needed to understand the complex relationship between inflammatory arthritis, insulin resistance, glucocorticoids, and metabolic pathways.

\section{Supplementary information}

Supplementary information accompanies this paper at https://doi.org/10. 1186/s41927-020-00138-3.

Additional file 1: Table S1. Baseline Characteristics: Diabetes Mellitus Criteria Cohort*. Table S2. Associations Between Treatment Initiation and Change in $\mathrm{HbA} 1 \mathrm{C}$ in Patients in the Diabetes Mellitus Criteria Cohort*. Table S3. Associations Between Treatment Initiation and Change in $\mathrm{HbA} 1 \mathrm{c}$ in either PSA, RA, or AS Patients with Baseline $\mathrm{HbA1c} \geq$ 7. Table S4. Sensitivity Analyses in the HbA1C $>=7$ Cohort. Table S5. Associations Between Treatment Initiation and Change in $\mathrm{HbA} 1 \mathrm{c}$ in either PsA, RA, or AS Patients in the Diabetes Mellitus Criteria Cohort*. Table S6. Sensitivity Analysis in the DM Criteria Cohort. Figure S1. Change in $\mathrm{HbA} 1 \mathrm{c}$ in baseline $\mathrm{A} 1 \mathrm{c} \geq 7$ cohort after TNFi, MTX, or Metformin Initiation. Figure S2. Change in $\mathrm{HbA1c}$ in DM Criteria Cohort after TNFi, MTX, or Metformin Initiation.

\section{Abbreviations}

AS: Ankylosing spondylitis; BMI: Body mass index; CAD: Coronary artery disease; CHF: Congestive heart failure; CKD: Chronic kidney disease; COPD: Chronic obstructive pulmonary disease; CTD: Connective tissue disease; FPG: Fasting plasma glucose; HbA1c: Hemoglobin A1c; ICD: International classification of disease; MTX: Methotrexate; PSA: Psoriatic arthritis: RA: Rheumatoid arthritis; SMD: Standardized mean difference; TNFi: Tumor necrosis factor inhibitor

\section{Acknowledgements}

We thank Tori Fischer for editorial assistance.

\section{Authors' contributions}

$A O, S M, J B$, and MG designed the study, SM, CB, and MD acquired and analyzed the data, All authors assisted in data interpretation and reviewed and edited the full manuscript. All approved the final version.

\section{Funding}

This work was supported by a grant from the McCabe Foundation. Santhi Mantravadi was supported by National Institutes of Health Postdoctoral training grant T32GM008562. Alexis Ogdie is supported by K23 AR063764, R01 AR072363 and the Rheumatology Research Foundation. Joshua Baker is supported by a VA Clinical Science Research and Development Career Development Award (IK2 CX000955) and Merit Award (I01 CX001703). Michael George is supported by K23 AR073931 and the Rheumatology Research Foundation. None of the funding bodies had any role in the study.

Availability of data and materials

Data can be obtained from Optum's de-identified Clinformatics ${ }^{\circledR}$ Data Mart Database.

Ethics approval and consent to participate

This study was considered exempt by the University of Pennsylvania Institutional Review Board.

\section{Consent for publication}

Not applicable.

\section{Competing interests}

Santhi Mantravadi is now employed by Janssen Research \& Development, L.L.C. Alexis Ogdie has served as a consultant for Abbvie, Amgen, BMS, Celgene, Corrona, Janssen, Lilly, Novartis, Pfizer, and Takeda and has received grants to the University of Pennsylvania from Pfizer and Novartis and to Forward from Amgen. Her husband has received royalties from Novartis. Joshua Baker has served as a consultant for BMS and Corrona.

\section{Author details}

${ }^{1}$ Department of Pharmacology and Experimental Therapeutics, Thomas Jefferson University, 132 South 10th Street, 1170 Main Building, Philadelphia, PA 19107-5244, USA. ²Department of Medicine, Division of Rheumatology, Perelman School of Medicine, University of Pennsylvania, White Building Rm 5023, 3400 Spruce St, Philadelphia, PA 19104, USA. ${ }^{3}$ Department of Biostatistics, Epidemiology, and Informatics, Division of Rheumatology, Perelman School of Medicine, University of Pennsylvania, 423 Guardian Dr, Philadelphia, PA 19104, USA.

Received: 11 March 2020 Accepted: 6 May 2020

Published online: 02 September 2020

\section{References}

1. Ogdie A, Schwartzman S, Husni ME. Recognizing and managing comorbidities in psoriatic arthritis. Curr Opin Rheumatol. 2015;27(2):118-26.

2. Ogdie A, Yu Y, Haynes K, Love TJ, Maliha S, Jiang Y, et al. Risk of major cardiovascular events in patients with psoriatic arthritis, psoriasis and rheumatoid arthritis: a population-based cohort study. Ann Rheum Dis. 2015;74(2):326-32

3. Ozen G, Pedro S, Holmqvist ME, Avery M, Wolfe F, Michaud K. Risk of diabetes mellitus associated with disease-modifying antirheumatic drugs and statins in rheumatoid arthritis. Ann Rheum Dis. 2017;76(5):848-54.

4. Bremander A, Petersson IF, Bergman S, Englund M. Population-based estimates of common comorbidities and cardiovascular disease in ankylosing spondylitis. Arthritis Care Res. 2011;63(4):550-6.

5. Brophy S, Cooksey R, Atkinson M, Zhou SM, Husain MJ, Macey S, et al. No increased rate of acute myocardial infarction or stroke among patients with ankylosing spondylitis-a retrospective cohort study using routine data. Semin Arthritis Rheum. 2012:42(2):140-5.

6. Chen HH, Yeh SY, Chen HY, Lin CL, Sung FC, Kao CH. Ankylosing spondylitis and other inflammatory spondyloarthritis increase the risk of developing type 2 diabetes in an Asian population. Rheumatol Int. 2014;34(2):265-70. 
7. Han C, Robinson DW Jr, Hackett MV, Paramore LC, Fraeman KH, Bala MV Cardiovascular disease and risk factors in patients with rheumatoid arthritis, psoriatic arthritis, and ankylosing spondylitis. J Rheumatol. 2006;33(11):216772.

8. Jafri K, Bartels CM, Shin D, Gelfand JM, Ogdie A. Incidence and Management of Cardiovascular Risk Factors in psoriatic arthritis and rheumatoid arthritis: a population-based study. Arthritis Care Res. 2017;69(1):51-7.

9. Coates LC, FitzGerald O, Helliwell PS, Paul C. Psoriasis, psoriatic arthritis, and rheumatoid arthritis: is all inflammation the same? Semin Arthritis Rheum. 2016;46(3):291-304.

10. Schett G, Coates LC, Ash ZR, Finzel S, Conaghan PG. Structural damage in rheumatoid arthritis, psoriatic arthritis, and ankylosing spondylitis: traditional views, novel insights gained from TNF blockade, and concepts for the future. Arthritis Res Therapy. 2011;13(Suppl 1):S4

11. Schett G, Gravallese E. Bone erosion in rheumatoid arthritis: mechanisms, diagnosis and treatment. Nat Rev Rheumatol. 2012;8(11):656-64.

12. Nunemaker CS. Considerations for defining cytokine dose, duration, and milieu that are appropriate for modeling chronic low-grade inflammation in type 2 diabetes. J Diabetes Res. 2016;2016:2846570.

13. Tam LS, Tomlinson B, Chu TT, Li M, Leung YY, Kwok LW, et al. Cardiovascular risk profile of patients with psoriatic arthritis compared to controls--the role of inflammation. Rheumatology (Oxford, England). 2008; 47(5):718-23.

14. Solomon SS, Buss N, Shull J, Monnier S, Majumdar G, Wu J, et al. Proteome of $\mathrm{H}-411 \mathrm{E}$ (liver) cells exposed to insulin and tumor necrosis factor-alpha: analysis of proteins involved in insulin resistance. J Lab Clin Med. 2005; 145(5):275-83.

15. Solomon SS, Odunusi O, Carrigan D, Majumdar G, Kakoola D, Lenchik NI, et al. TNF-alpha inhibits insulin action in liver and adipose tissue: a model of metabolic syndrome. Horm Metab Res. 2010;42(2):115-21.

16. Hotamisligil GS, Peraldi P, Budavari A, Ellis R, White MF, Spiegelman BM. IRS1-mediated inhibition of insulin receptor tyrosine kinase activity in TNFalpha- and obesity-induced insulin resistance. Science (New York, NY). 1996; 271(5249):665-8

17. Aguirre V, Uchida T, Yenush L, Davis R, White MF. The c-Jun NH(2)-terminal kinase promotes insulin resistance during association with insulin receptor substrate-1 and phosphorylation of Ser (307). J Biol Chem. 2000;275(12): 9047-54.

18. Seriolo B, Ferrone C, Cutolo M. Longterm anti-tumor necrosis factor-alpha treatment in patients with refractory rheumatoid arthritis: relationship between insulin resistance and disease activity. J Rheumatol. 2008;35(2):355-7.

19. Stagakis I, Bertsias G, Karvounaris S, Kavousanaki M, Virla D, Raptopoulou A, et al. Anti-tumor necrosis factor therapy improves insulin resistance, beta cell function and insulin signaling in active rheumatoid arthritis patients with high insulin resistance. Arthritis Res Therapy. 2012;14(3):R141.

20. Stavropoulos-Kalinoglou A, Metsios GS, Panoulas VF, Nightingale P, Koutedakis $Y$, Kitas GD. Anti-tumour necrosis factor alpha therapy improves insulin sensitivity in normal-weight but not in obese patients with rheumatoid arthritis. Arthritis Res Therapy. 2012;14(4):R160.

21. Oguz FM, Oguz A, Uzunlulu M. The effect of infliximab treatment on insulin resistance in patients with rheumatoid arthritis. Acta Clin Belg. 2007;62(4): 218-22.

22. Kiortsis DN, Mavridis AK, Vasakos S, Nikas SN, Drosos AA. Effects of infliximab treatment on insulin resistance in patients with rheumatoid arthritis and ankylosing spondylitis. Ann Rheum Dis. 2005;64(5):765-6.

23. Perdan-Pirkmajer K, Pirkmajer S, Thevis M, Thomas A, Praprotnik S, Hocevar A, et al. Methotrexate reduces HbAlc concentration but does not produce chronic accumulation of ZMP in patients with rheumatoid or psoriatic arthritis. Scand J Rheumatol. 2016;45(5):347-55.

24. Toms TE, Panoulas VF, John H, Douglas KM, Kitas GD. Methotrexate therapy associates with reduced prevalence of the metabolic syndrome in rheumatoid arthritis patients over the age of 60- more than just an antiinflammatory effect? A cross sectional study. Arthritis Res Therapy. 2009; 11(4):R110.

25. Solomon DH, Massarotti E, Garg R, Liu J, Canning C, Schneeweiss S. Association between disease-modifying antirheumatic drugs and diabetes risk in patients with rheumatoid arthritis and psoriasis. Jama. 2011;305(24): 2525-31.

26. Cuchacovich R, Espinoza LR. Does TNF-alpha blockade play any role in cardiovascular risk among rheumatoid arthritis (RA) patients? Clin Rheumatol. 2009;28(10):1217-20.
27. Brunelli SM, Gagne JJ, Huybrechts KF, Wang SV, Patrick AR, Rothman KJ, et al. Estimation using all available covariate information versus a fixed lookback window for dichotomous covariates. Pharmacoepidemiol Drug Saf. 2013:22(5):542-50.

28. Connolly JG, Schneeweiss S, Glynn RJ, Gagne JJ. Quantifying bias reduction with fixed-duration versus all-available covariate assessment periods. Pharmacoepidemiol Drug Saf. 2019;28(5):665-70.

29. Nakasian SS, Rassen JA, Franklin JM. Effects of expanding the look-back period to all available data in the assessment of covariates. Pharmacoepidemiol Drug Saf. 2017;26(8):890-9.

30. Kim SY, Servi A, Polinski JM, Mogun H, Weinblatt ME, Katz JN, et al. Validation of rheumatoid arthritis diagnoses in health care utilization data. Arthritis Res Therapy. 2011;13(1):R32.

31. Ogdie A, Alehashemi S, Love TJ, Jiang Y, Haynes K, Hennessy S, et al. Validity of psoriatic arthritis and capture of disease modifying antirheumatic drugs in the health improvement network. Pharmacoepidemiol Drug Saf. 2014; 23(9):918-22.

32. Dubreuil M, Peloquin C, Zhang Y, Choi HK, Inman RD, Neogi T. Validity of ankylosing spondylitis diagnoses in the health improvement network. Pharmacoepidemiol Drug Saf. 2016;25(4):399-404.

33. Chung CP, Rohan P, Krishnaswami S, McPheeters ML. A systematic review of validated methods for identifying patients with rheumatoid arthritis using administrative or claims data. Vaccine. 2013;31(Suppl 10):K41-61.

34. Lindstrom U, Exarchou S, Sigurdardottir V, Sundstrom B, Askling J, Eriksson JK, et al. Validity of ankylosing spondylitis and undifferentiated spondyloarthritis diagnoses in the Swedish National Patient Register. Scand J Rheumatol. 2015;44(5):369-76.

35. Dobson-Belaire W, Goodfield J, Borrelli R, Liu FF, Khan ZM. Identifying psoriasis and psoriatic arthritis patients in retrospective databases when diagnosis codes are not available: a validation study comparing medication/prescriber visitbased algorithms with diagnosis codes. Value Health. 2018;21(1):110-6.

36. Richesson RL, Rusincovitch SA, Wixted D, Batch BC, Feinglos MN, Miranda $\mathrm{ML}$, et al. A comparison of phenotype definitions for diabetes mellitus. J Am Med Inform Assoc. 2013;20(e2):e319-26.

37. CMMS. [Available from: https://www.ccwdata.org/web/guest/conditioncategories.

38. Hebert PL, Geiss LS, Tierney EF, Engelgau MM, Yawn BP, McBean AM. Identifying persons with diabetes using Medicare claims data. Am J Med Qual. 1999;14(6):270-7.

39. O'Connor PJ, Rush WA, Pronk NP, Cherney LM. Identifying diabetes mellitus or heart disease among health maintenance organization members: sensitivity, specificity, predictive value, and cost of survey and database methods. Am J Manag Care. 1998;4(3):335-42.

40. Margolis DJ, Malay DS, Hoffstad OJ, Leonard CE, MaCurdy T, Lopez de Nava $K$, et al. Prevalence of diabetes, diabetic foot ulcer, and lower extremity amputation among Medicare beneficiaries, 2006 to 2008: data points \#1. Rockville: Agency for Healthcare Research and Quality (US); Data Points Publication Series; 2011.

41. Kirkman MS, Briscoe VJ, Clark N, Florez H, Haas LB, Halter JB, et al. Diabetes in older adults. Diabetes Care. 2012;35(12):2650-64.

42. Campbell NR, Gilbert RE, Leiter LA, Larochelle P, Tobe S, Chockalingam A, et al. Hypertension in people with type 2 diabetes: update on pharmacologic management. Can Fam Physician. 2011:57(9):997-1002 e347-53.

43. Dixit AK, Dey R, Suresh A, Chaudhuri S, Panda AK, Mitra A, et al. The prevalence of dyslipidemia in patients with diabetes mellitus of ayurveda hospital. J Diab Metab Disord. 2014;13:58.

44. Schofield JD, Liu Y, Rao-Balakrishna P, Malik RA, Soran H. Diabetes dyslipidemia. Diab Therapy. 2016;7(2):203-19.

45. Gisondi P, Cotena C, Tessari G, Girolomoni G. Anti-tumour necrosis factoralpha therapy increases body weight in patients with chronic plaque psoriasis: a retrospective cohort study. J Eur Acad DermatolVenereol. 2008; 22(3):341-4.

46. Marra M, Campanati A, Testa R, Sirolla C, Bonfigli AR, Franceschi C, et al. Effect of etanercept on insulin sensitivity in nine patients with psoriasis. Int $J$ Immunopathol Pharmacol. 2007;20(4):731-6.

47. Gupta-Ganguli M, Cox K, Means B, Gerling I, Solomon SS. Does therapy with anti-TNF-alpha improve glucose tolerance and control in patients with type 2 diabetes? Diabetes Care. 2011;34(7):e121.

48. Deodhar A, Bitman B, Yang Y, Collier DH. The effect of etanercept on traditional metabolic risk factors for cardiovascular disease in patients with rheumatoid arthritis. Clin Rheumatol. 2016;35(12):3045-52. 
49. Otsuka Y, Kiyohara C, Kashiwado Y, Sawabe T, Nagano S, Kimoto Y, et al. Effects of tumor necrosis factor inhibitors and tocilizumab on the glycosylated hemoglobin levels in patients with rheumatoid arthritis; an observational study. PLoS One. 2018;13(4):e0196368.

50. Wu JJ, Rowan CG, Bebchuk JD, Anthony MS. No association between TNF inhibitor and methotrexate therapy versus methotrexate in changes in hemoglobin $\mathrm{A} 1 \mathrm{C}$ and fasting glucose among psoriasis, psoriatic arthritis, and rheumatoid arthritis patients. J Drugs Dermatol. 2015;14(2):159-66.

51. da Silva BS, Bonfa E, de Moraes JC, Saad CG, Ribeiro AC, Goncalves CR, et al. Effects of anti-TNF therapy on glucose metabolism in patients with ankylosing spondylitis, psoriatic arthritis or juvenile idiopathic arthritis. Biologicals. 2010;38(5):567-9.

\section{Publisher's Note}

Springer Nature remains neutral with regard to jurisdictional claims in published maps and institutional affiliations.

Ready to submit your research? Choose BMC and benefit from:

- fast, convenient online submission

- thorough peer review by experienced researchers in your field

- rapid publication on acceptance

- support for research data, including large and complex data types

- gold Open Access which fosters wider collaboration and increased citations

- maximum visibility for your research: over $100 \mathrm{M}$ website views per year

At $\mathrm{BMC}$, research is always in progress.

Learn more biomedcentral.com/submissions 